\title{
O PROCESSO DE MILITARIZAÇÃO DE UMA ESCOLA ESTADUAL PÚBLICA EM GOIÁS
}

\author{
Miriam Fábia Alves ${ }^{1}$ \\ Neusa Sousa RêGo Ferreira ${ }^{2,3}$
}

\begin{abstract}
RESUMO: O objetivo deste artigo é analisar o processo de militarização de uma escola estadual pública, ocorrido no ano de 2015, para compreender as implicações da expansão do modelo militar no sistema público de ensino goiano. O estudo de caso contou com pesquisa documental e de campo, tendo como lócus um colégio estadual da polícia militar de Goiás, onde os dados foram coletados por meio de questionários abertos e fechados aplicados aos alunos, pais/responsáveis e professores. Concluiu-se que o processo de militarização tem possibilitado um modelo de escolarização excludente que conta com pagamento de contribuição financeira mensal pelos pais, além de desobrigar o estado de oferecer a educação como um direito de todos.
\end{abstract}

Palavras-chave: Militarização. Escola pública. Colégio Estadual da Polícia Militar de Goiás. Goiás.

\section{THE MILITARIZATION PROCESS OF A PUBLIC STATE SCHOOL IN GOIÁS}

\begin{abstract}
The aim of this article is to analyze the process of militarization of a public state school in 2015, in order to comprehend the implications of the expansion of the military model in the public education system in Goiás. The case study included documentary and field research. The research locus was a State School of the Military Police of Goiás, where data were collected through open and closed questionnaires applied to students, parents/guardians, and teachers. It is concluded that the militarization process has allowed a model of exclusionary schooling that requires the payment of a monthly financial contributions by parents, in addition to discharging the state from offering education as a right to all.
\end{abstract}

Keywords: Militarization. Public school. State School of the Military Police of Goiás. Goiás.

1.Universidade Federal de Goiás, Programa de Pós-Graduação em Educação - Goiânia (GO), Brasil. E-mail: miriamfabia@gmail.com 2.Secretaria Municipal de Educação de Aparecida de Goiânia - Aparecida de Goiânia (GO), Brasil. E-mail: neusass2012@hotmail.com 3.Secretaria de Estado de Educação, Cultura e Esporte de Goiás - Goiânia (GO), Brasil. E-mail: neusass2012@hotmail.com

Este artigo apresenta resultados do projeto de mestrado intitulado Militarização das escolas estaduais em Goiás: um estudo de caso da implantação de um CPMG em Aparecida de Goiânia, aprovado pelo Comitê de Ética da Universidade Federal de Goiás em 2017. 


\title{
EL PROCESO DE MILITARIZACIÓN DE UNA ESCUELA PÚBLICA ESTATAL EN GOIÁS
}

\begin{abstract}
RESUMEN: El objetivo de este artículo es analizar el proceso de militarización ocurrido en el año 2015 en una escuela estatal pública, para comprender así, las implicaciones de la expansión del modelo militar en el sistema público de enseñanza en Goiás. El estudio de caso contó con investigación documental y de campo, teniendo como locus de investigación un Colegio Estatal de la Policía Militar de Goiás, donde los datos fueron recolectados por medio de cuestionarios abiertos y cerrados aplicados a los alumnos, padres/responsables y profesores. Se concluye que el proceso de militarización ha posibilitado un modelo de escolarización excluyente que cuenta con el pago de contribución financiera mensual de los padres, además de eximir al estado de su responsabilidad de otorgar educación como derecho de todos.
\end{abstract}

Palabras-clave: Militarización. Escuela pública. Colegio Estadual de la Policía Militar de Goiás. Goiás.

\section{Introdução}

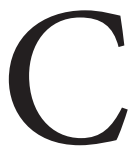

om o país sob nova liderança, o ano de 2019 tem se caracterizado pelo aumento das taxas de desemprego, da insegurança financeira e social e da banalização da violência, que toma proporções assustadoras. Os efeitos da Emenda Constitucional n 95/2016 já começam a ser sentidos pela população brasileira e impactam a saúde e a segurança pública, a educação e programas de distribuição de renda como o Bolsa Família. Cresce a ameaça aos direitos sociais adquiridos com muitas lutas, sobretudo no campo trabalhista e previdenciário. A palavra corte é usada como justificativa pelo atual governo para indicar que se gastava muito e que agora é necessária uma política de austeridade fiscal. No âmbito educacional, de maneira especial, estamos presenciando cortes no orçamento público para a educação superior, a pesquisa, a ciência e a tecnologia. No campo simbólico, destacamos o ataque aos professores, apresentados pelo governo e seus seguidores como doutrinadores e incompetentes. Esses agentes insistem na narrativa de desvalorização social da universidade e da escola pública, anunciando que esses modelos estão falidos e precisam ser substituídos por outros (STECCA, 2019).

Nesse cenário, em que o desmonte caracteriza o cenário educacional, ganham relevo as chamadas escolas cívico-militares. Essas instituições recebem nomenclaturas distintas em alguns estados brasileiros: escolas militares, colégios militares, colégios da Polícia Militar (PM). Em Goiás, o processo de militarização das escolas, ou seja, a entrega das escolas públicas estaduais à gestão da PM, vem dominando a cena educacional. O objetivo deste artigo é analisar o processo de militarização de uma escola estadual em Goiás, ocorrido no ano de 2015, para compreender a motivação de sua origem e sua expansão no sistema público de ensino, bem como as justificativas e a história dos colégios militares de Goiás.

O estudo de caso teve como lócus de pesquisa um colégio estadual da PM de Goiás (CEPMG) de Aparecida de Goiânia. Os dados foram coletados entre setembro e novembro de 2017 por meio de questionários abertos e fechados aplicados aos alunos (amostra constituída de 74 questionários aos estudantes do segundo ano do ensino médio, sendo 39 do período matutino e 35 do noturno) e de questionários abertos aplicados aos pais/responsáveis (32 questionários respondidos) e professores (amostra com 15 questionários devolvidos, do total de 25 aplicados). 
O artigo divide-se em duas seções. Na primeira, discutimos o processo de militarização das escolas estaduais, cuja justificativa é o medo da violência. Na segunda, mostramos como está acontecendo o processo de militarização de uma escola estadual em Goiás.

\section{A militarização em Goiás: o medo como justificativa para a expansão dos colégios militares}

Os colégios militares de Goiás foram criados em 18 de junho de 1976, por meio da Lei no 8.125 (GOVERNO DO ESTADO DE GOIÁS, 1976), sancionada pelo governador biônico Irapuan Costa Júnior. Em seu artigo 23, inciso I, letra b, criou-se o CEPMG, cuja efetivação, porém, apenas se deu 23 anos após sua idealização, ou seja, em 1999, quando o primeiro CEPMG iniciou suas atividades escolares com os civis. Para Alves, Toschi e Ferreira (2018, p. 274), a "Lei de 1976 não cria um colégio militar para atender civis. Ao contrário, ela tem um público-alvo bem definido: os dependentes do corpo de oficiais pertencentes à Polícia Militar, desejo concretizado apenas em 1998". Assim, originalmente não havia a pretensão de se fazer da escola estadual um colégio gerido pela PM como política pública praticada pelo governo de Goiás.

Até 2007, o processo de implementação de colégios transferidos para a PM de Goiás caminhou mais discretamente, e contabilizava-se o total de seis unidades de colégios da PM. A partir de então, houve uma escalada vertiginosa no crescimento do número desses colégios. Nos anos de 2013 (com a criação de 18 unidades de CPMG), 2015 (15 unidades) e 2017 (com 25 unidades), atingiu-se um pico na elaboração de leis e na implementação de unidades criadas anteriormente. As justificativas para esse crescimento estão associadas ao pós-movimento grevista, no caso de 2013 e 2015 e especificamente em 2017, à tentativa do governador Marconi Perillo (Partido da Social Democracia Brasileira - PSDB) de se eleger ao senado e fazer com que seu sucessor no governo de Goiás fosse o seu vice no mandato de 2015-2018 (ALVES; TOSCHI; FERREIRA, 2018). Essas associações fazem-nos refletir sobre as intencionalidades que permeiam o movimento de militarização das escolas em Goiás.

A expansão do número de colégios militarizados levou à criação de um subsistema de ensino na rede pública estadual de Goiás. O governo do estado, por meio da Lei no 19.679, de 13 de junho de 2017 (GOVERNO DO ESTADO DE GOIÁS, 2017), criou a Superintendência de Coordenação dos Colégios Militares e a Gerência de Coordenação dos Colégios Militares, atribuindo novo status a esses colégios e expressando uma nova lógica organizacional da rede estadual de Goiás.

De acordo com o organograma da Secretaria de Estado de Educação, Cultura e Esporte (Seduce), disponível no site do órgão, no ano de 2018, a Superintendência de Segurança Escolar e Colégio Militar passou a estar diretamente ligada à Superintendência Executiva de Educação, composta de militares do alto escalão da PM de Goiás - coronel, tenente-coronel e major - , que ocupam as funções de superintendente geral, gerente de colégio militar e gerente de segurança pública. Essa reorganização da rede estadual de ensino goiana indica que o modelo de militarização do ensino ganha cada vez mais força. Por isso, torna-se fundamental compreendê-lo.

Mas o que justificaria a expansão tão acelerada dos colégios militares nos últimos anos? Como entender os investimentos financeiros e simbólicos nesse modelo de escola pública estadual? Para Alves, Toschi e Ferreira (2018), a expansão atende a um projeto eleitoral do governo de Goiás, e por esse motivo o número de criação de colégios teria crescido acentuadamente em períodos pré-eleitorais. Por outro lado, a narrativa construída acerca dos colégios militares nos últimos 20 anos, por diferentes interlocutores hegemônicos (governo do estado, mídia, Polícia Militar) enfatizam o sucesso dessas escolas em dois quesitos centrais: impor a disciplina e o bom rendimento dos alunos nas provas e exames nacionais. Essa narrativa tem ganhado a adesão da população e os colégios passaram a ser objeto de desejo de muitas famílias, as quais 
desejam uma escola de qualidade e segura para os seus filhos (ALVES; TOSCHI; FERREIRA, 2018, p. 283). A narrativa de uma escola segura e que prima pela disciplina tem sido largamente utilizada para justificar a militarização da escola pública. Por diversas vezes, a sua ligação com a contenção da violência esteve presente na fala dos sujeitos com os quais mantivemos contato antes e ao longo da pesquisa. Prevaleciam as narrativas do jovem e do adolescente que necessitavam ser contidos pelo estabelecimento de uma ordem social suficientemente capaz de enquadrá-los e de contê-los.

Oliveira (2016) estabelece uma clara relação entre o discurso a favor dos colégios militares e o mito da violência e da criminalidade associada principalmente à juventude:

O discurso da segurança pública tem se tornado um instrumento importante para muitos governantes. Por meio dele tem sido possível criar mecanismos que permitem um maior controle dos movimentos sociais, a ampliação da capacidade de monitoramento dos grupos de oposição, assim como de acompanhamento de setores apontados como socialmente incômodos como, por exemplo, as pessoas em situação de rua, migrantes estrangeiros de países considerados pobres ou arrasados, além dos movimentos sociais de contestação (OLIVEIRA, 2016, p. 42-43).

Ainda segundo Oliveira (2016), o discurso do medo não tem compromisso com a verdade e estabelece-se mais pelo movimento falacioso do que pelos fatos. Nesse sentido, a grande mídia exerce um papel importante na inculcação da existência de uma sociedade violenta e legitima, assim, a implementação do controle social, sobretudo da juventude. Pautados nesse controle social, muitos governantes têm fomentado políticas públicas - sutis e legitimadas - que caminham na direção da submissão dos cidadãos e contribuem para a manutenção do poder e do controle sobre eles.

Por sua vez, Souza (2017, p. 11) esclarece a importância da legitimação do poder na sociedade, aqui denominado por ele de poder social:

A questão do poder é a questão central de toda sociedade. A razão é simples. É ela quem nos irá dizer quem manda e quem obedece, quem fica com os privilégios e que é abandonado e excluído. Assim, para se conhecer uma sociedade, é necessário reconstruir os meandros do processo que permite a reprodução do poder social real. [...] O exercício do poder social real tem de ser legitimado. Ninguém obedece sem razão. (SOUZA, 2017, p. 11).

Oliveira (2016) apresenta algumas narrativas de mito e de cultura do medo utilizadas pelos governantes para dar respaldo às ações de controle social e, no caso da expansão dos CEPMG, legitimar esse modelo militar de educação de jovens e adolescentes. Dado o incremento do processo de transferência das escolas para a PM, concordamos com o autor, para quem "a cultura do medo e o cenário de violência como fontes no processo de fortalecimento da ideia de que temos que preparar nossas instituições para agirem de forma dura contra as 'ameaças'” (OLIVEIRA, 2016, p. 46).

Nesse sentido, os governantes pautam-se na ideia de que os jovens de hoje são mais violentos do que os de antigamente, bem como na associação desses jovens com o mundo da criminalidade. Parte da sociedade, induzida pelo poder de persuasão e convencimento das mídias em geral e do discurso oficial, legitima as propostas pedagógicas de endurecimento do controle disciplinar e da repressão por meio da escola, o que constitui um risco para a formação humanística da juventude, uma vez que a "pedagogia militarista" se sobrepõe à pedagogia humanística (OLIVEIRA, 2016).

Sob o discurso do controle da violência, a defesa da ordem preconizada pelo poder público e 
assumida pela PM objetiva a manutenção de uma ordem social marcada pelas desigualdades sociais e econômicas, que supõe o controle da juventude, dos movimentos sociais e das periferias que se opõem a essa realidade excludente.

\section{O processo de militarização de uma escola pública: o caso de um CEPMG em Aparecida de Goiânia}

A escola estadual militarizada, aqui denominada de CEPMG Cerrado ${ }^{1}$, situada em Aparecida de Goiânia, caracterizava-se à época do processo de militarização - ou seja, da transferência da escola para a PM - por condições físicas e estruturais precárias e pelo engajamento político de seu quadro de professores e funcionários administrativos. Esses profissionais também sobressaíam na região pela realização de atividades culturais que envolviam a comunidade local, como caminhadas e passeios no setor. A escola ganhou visibilidade com o engajamento nas greves ocorridas nos anos de 2012 e 2015, quando alguns professores se destacaram à frente da luta pela educação pública no cenário goiano como membros do grupo Mobilização dos Professores de Goiás.

Em 2015, o ano letivo foi interrompido em várias escolas estaduais por causa da greve deflagrada em 13 de maio, que se encerrou em princípios de agosto. No período de férias escolares, em 22 de julho de 2015, o governo Marconi Perillo sancionou a Lei no 18.967 (GOVERNO DO ESTADO DE GOIÁS, 2015), que transformou sete escolas estaduais em colégios militares. Ao retornarem das férias, os profissionais dessas escolas depararam com uma nova realidade: a gestão militar implantada via despacho governamental.

Na primeira reunião para a apresentação do novo grupo gestor do recém-formado CEPMG Cerrado, realizada em 3 de agosto de 2015, o comandante-diretor major Reinaldo de Melo Barros esclareceu ser terminantemente proibida a participação de professores, funcionários administrativos e alunos em movimentos grevistas. Esse primeiro contato entre civis e militares foi permeado pela sobreposição destes àqueles, numa relação de poder e de submissão dos mais fortes sobre os mais fracos, e pelo silêncio ensurdecedor no ambiente escolar. Assim, colocou-se em contradição o termo parceria, empregado tanto pela Seduce como pelos militares para se referir ao trabalho desenvolvido por essas duas secretarias no ambiente escolar, dada a constante vigilância dos militares sobre os civis, conforme relatado pelos docentes:

Não foram poucas as vezes que me surpreendi com algum policial fardado à porta da sala de aula em que eu lecionava, algumas vezes até adentrando-a, sem ao menos justificar tal procedimento, o que acarretava constrangimento a mim e aos estudantes (Professor C).

Já houve casos da professora de História estar trabalhando sobre a ditadura militar e um militar do turno noturno ficar na porta observando o que ela iria falar (Professor A).

Os professores apresentam uma narrativa muito utilizada pelo governo estadual que afirma que os militares cuidam apenas da gestão escolar. Isso não se confirma na pesquisa realizada. A presença dos militares no ambiente escolar tem impacto na prática docente, gerando um ambiente de controle e vigilância sobre o professor. Esse fato ocasionou muitos pedidos de remoção de professores - expressamente proibida, conforme orientação da Lei no 18.967, de 22 de julho de 2015 (GOVERNO DO ESTADO DE GOIÁS, 2015) - e certa rivalidade entre os integrantes dessas duas secretarias: 
Na verdade, a primeira mudança que sentimos é que, a partir da militarização da escola, ela deixa de ser da Secretaria de Educação e passa a ser da Secretaria de Segurança Pública. Os nossos anseios deixam de ser consultados. Temos que obedecer às ordens de pessoas que muitas vezes não entendem de educação (Professor I).

Sem falar que não admitiria alguém sem nenhum conhecimento na área de educação intrometer-se no meu trabalho, [para] o qual fui preparado e sempre faço estudos para melhorar a relação ensino-aprendizagem (Professor B).

A principal mudança ocorrida na escola foi a afirmação e valorização da hierarquia. Não sendo dito claramente, mas facilmente observável, os militares de qualquer patente estão acima dos civis (Professor J).

Agora existe um militar responsável pela área pedagógica (Detalhe: a mesma não entendia bulhufas do que estava falando) (Professor A).

As narrativas dos professores indicam que se estabelece uma diferenciação entre as escolas da rede estadual. Santos (2016) afirma que passamos a acompanhar uma competição desleal entre escolas geridas por civis e colégios administrados por policiais. Isso nos leva a refletir sobre a existência de fronteiras entre elas. Segundo o autor, concomitantemente à separação desses dois tipos de escola, surgem a competição e a comparação inevitável dos alunos, disputa na qual cada modelo apresenta características próprias e defensores distintos: "Estou nesta escola porque meus pais mandam. Se eu pudesse decidir, não estudaria aqui. Ia para o Elmar. Acho que a polícia deveria cuidar dos bandidos. Não sou bandido" (Aluno A).

Com a implementação do modelo militar, os alunos passaram a ser enquadrados no GR-8, sistema de controle disciplinar comum a todas as unidades de CEPMG. Nele, os estudantes recebem a nota 8,0 no início do ano e, se eles se envolvem em situações que descumprem o regimento interno, têm essa média diminuída. Ao atingir a pontuação insuficiente, são submetidos ao termo de ajustamento de conduta (TAC), que deve ser assinado pelo aluno e por seu responsável. Além disso, caso o estudante não se adapte ao modelo militar de educar, pode vir a ser convidado a se retirar da unidade escolar militar por meio do conselho disciplinar, que avalia a permanência ou não do aluno na unidade. Os estudantes associam o interior da instituição escolar ao trabalho realizado pela PM na sociedade em geral. A chamada dos alunos à divisão disciplinar passou a ser pejorativamente denominada por eles de boletim de ocorrência (BO), e o registro da indisciplina dos alunos no GR-8 recebeu o apelido de fichamento. Corriqueiramente, os estudantes chamam os colegas de ficha suja, P2 (policial do serviço de inteligência da PM), fichado e registrado, entre outros adjetivos, naturalizando, assim, uma linguagem característica da polícia, estritamente militar.

No que concerne à relação entre pais e movimento de resistência, aqueles que discordavam do modelo ou que não tinham condições financeiras de manter os filhos no colégio militar acabaram procurando outra unidade escolar, de modo a abrir vagas para os pais/responsáveis favoráveis a esse modelo de ensino. Atualmente, os pais/responsáveis atendidos pelo CEPMG Cerrado atribuem a permanência no colégio à qualidade da educação ali oferecida, ao ensino rigoroso, à segurança, à disciplina, ao ensino de regras, à cultura do patriotismo e também à possibilidade de um "ensino melhor" e de um "futuro brilhante" para seus(as) filhos(as): "Porque eu sei que é o melhor ensino. Gosto do colégio e fico tranquila sabendo que ele está sendo preparado em um bom colégio para o futuro. Lá tem segurança, bom desempenho, boas amizades. Aprende a se relacionar melhor com as pessoas" (Responsável 6).

Entre as justificativas dos pais/responsáveis para a procura/permanência no colégio, chama a atenção um dado no tocante àqueles que ingressaram no colégio após a transferência da gestão: a preponderância da 
disciplina. Esse ponto faz-nos refletir sobre a transferência da responsabilidade dessa formação, que deveria ser oferecida pelas famílias, para a escola, oferecida pelo estado. A estrutura física do colégio também sofreu alterações significativas nesses três primeiros anos de gestão militar, favorecidas principalmente pela cobrança de uma taxa mensal denominada de contribuição voluntária, cobrada pela Associação de Pais e Mestres (APM). O regimento interno dos CEPMG do ano letivo de 2017, no Título VII, artigo 159, classifica as contribuições doadas pelos pais/responsáveis como esporádicas e voluntárias. As esporádicas, mais comuns em situações de filantropias, festividades e competições escolares, são pauta também nas escolas geridas por civis e destinam-se ao provimento de material didático e a reparos de modo geral. A polêmica em torno das contribuições, no entanto, diz respeito à cobrança mensal de um valor previamente estipulado pela APM desses colégios, conforme disposto: “ $\$ 2^{\circ}$ Contribuição voluntária feita por cada pai ou responsável pelos alunos, durante o ano letivo, destinada a prover as despesas gerais do CPMG para a melhoria do ensino" (CEPMG, 2017).

A aplicabilidade do dinheiro proveniente da contribuição mensal é regulamentada no mesmo artigo:

$\S 3^{\circ}$ As contribuições voluntárias podem ainda ter as seguintes destinações:

I - aquisição da agenda escolar anual exclusiva do CPMG e carteira estudantil;

II - aquisição do uniforme adotado na escola;

III - ressarcimento de quaisquer danos patrimoniais comprovadamente causados pelo aluno (CEPMG, 2017).

A falta de comprometimento do governo de Goiás com a manutenção das condições físicas e estruturais dos prédios escolares públicos se evidencia no inciso III do artigo, que estabelece como finalidade "ressarcir danos patrimoniais" na unidade escolar. Essa concepção também está clara para os próprios comandantes-diretores das instituições militares².

Comumente acompanhada do termo "voluntária", entre aspas, a cobrança da taxa mensal tem gerado polêmica nos meios social e acadêmico. A esse respeito, o Comando de Ensino da PM esclareceu em uma entrevista que a voluntariedade se restringe à adesão opcional à APM existente em cada uma das unidades de CEPMG. Uma vez que o responsável tenha aderido a essa associação, entende-se que ele deve contribuir mensalmente com a quantia estabelecida em reunião pelos associados, até para prover o fornecimento de uniformes para os alunos carentes, conforme se pode perceber na fala do policial:

O uso do termo colocado entre aspas não se justifica. Existe voluntariedade na adesão da Associação de Pais e Mestres. Quem recebe essa contribuição é essa associação. Ninguém é obrigado a se associar, mas, uma vez associado, assume deveres junto a mesma. Essa associação vota um valor a ser pago mensalmente pelos associados. Caso o pai não queira se associar, não se inviabiliza a ida a escola ou outras questões. As contribuições recebidas por esta associação fomentam uma série de mudanças na comunidade escolar, dentre elas a aquisição de uniforme para pessoas carentes (Tenente-Coronel 1).

No início de cada ano letivo, os estudantes atendidos nos CEPMG recebem uma agenda escolar que contém o regimento interno. O artigo que tratava da contribuição mensal foi excluído na edição de 2018. De acordo com Coronel 1, isso se deu em virtude de orientação do Ministério Público do estado de Goiás (MP-GO), que se posicionou contrariamente à cobrança de valores e ao estabelecimento de cotas para dependentes de militares. No entanto, a orientação dada pelo MP-GO, para quem "mesmo a cobrança 
voluntária não pode existir em escolas públicas”" , não tem sido cumprida nos CEPMG. A cobrança das contribuições mensais continua a ser praticada.

Se, por um lado, parte dos pais/responsáveis atendidos nesses colégios questiona a contribuição mensal e a denuncia ao Ministério Público4, por outro existem os que saem em sua defesa e assumem para si a responsabilidade pela manutenção do prédio público onde seus filhos estudam. De acordo com as entrevistas realizadas com os pais/responsáveis durante a pesquisa, 100\% deles tinham conhecimento dos custos extras com os uniformes e outras despesas de manutenção dos estudantes no colégio e da contribuição mensal. Entre os qualitativos empregados por eles ao falarem da contribuição mensal, os termos "investimento na educação" e "melhoria da escola" predominaram nas respostas: "Ao ingressar no colégio, eu já sabia de todos estes gastos. E não vejo como gastos, mas sim como investimento, tanto no adquirir da farda como na contribuição" (Pai/Responsável, 13).

Outros pais concordam com o pagamento, mas têm claro que a manutenção dos prédios públicos deve ser do poder público: "O estado deveria arcar com estes custos. No entanto, como ele não o faz, nós fazemos pelos nossos filhos” (Pai/Responsável, 27).

Um diálogo com Tavares (2016) chama-nos a atenção para a ilegalidade dessa contribuição, já que o estado não pode pedir ou exigir contribuições porque tem receita própria:

E você não pode, como Estado, simplesmente pedir "contribuições" por aí. O dinheiro do poder público não funciona assim. Este é um Estado liberal-democrático, estado liberal-democrático tem "receita originária", quando o Estado aluga um terreno, presta um serviço e isso gera dinheiro etc. e "receita derivada", quando o estado multa alguém, ou arrecada tributos. A grande receita do Estado vem de tributos. O modo como esse dinheiro será gasto será discutido pelo Parlamento, e o Poder Executivo irá executar o que o parlamento decidir, podendo fazer contingenciamentos. Isso é norma cogente. Para quem não está familiarizado com esse chatíssimo vocabulário: isso é obrigatório, isso não tem discussão (TAVARES, 2016, p. 57).

Se os colégios contam com outra lógica de financiamento, é possível compreender por que as modificações na infraestrutura foram iniciadas logo nos primeiros 15 dias da chegada dos militares: "Inicialmente, passaram uma tinta nas paredes para demarcar território, pois 'ESCOLA MILITAR TEM QUE SER PINTADA DE MARROM' [...] e colocaram ar-condicionado primeiro onde ficam os militares. Com que objetivo? Eles precisam de mais conforto que os alunos" (Professor I).

No decorrer dos meses, o CEPMG Cerrado foi pintado seguindo o padrão de bege claro com detalhes em marrom, incorporado à área pública vizinha ao seu muro e beneficiado com a construção de uma quadra de esportes. Além disso, o seu espaço físico foi remodelado, de modo a favorecer a criação de diferentes departamentos administrativos individualizados, ocupados por policiais - mecanografia, recepção, sala do diretor-comandante, sala do subcomando, tesouraria, sala da divisão disciplinar, coordenação de merenda escolar, sala da APM e barbearia social. Instalaram-se sistemas de ar-condicionado em todas as dependências da administração e climatizadores em todas as salas de aula. Além disso, foram construídas uma ampla e ventilada biblioteca e uma sala de informática (que ainda aguarda a chegada de computadores). Foram construídos dois banheiros para uso exclusivo dos funcionários, um masculino e um feminino, e neles também foram instalados chuveiros elétricos. Renovaram-se todo o mobiliário do aluno - composto de mesa e cadeira - e parte do mobiliário geral da escola, e as lousas verdes nas salas foram substituídas por quadros brancos. O CEPMG Cerrado ainda foi contemplado com linha telefônica e internet para uso dos professores. O número de alunos frequentes passou de uma média de 600 para $879^{5}$. 
Embora os funcionários administrativos e os professores sejam unânimes em afirmar que o colégio passou por significativas transformações na estrutura física e no mobiliário, permanece a reclamação quanto ao aspecto pedagógico. Os docentes reclamam da falta de material pedagógico para facilitar seu trabalho. Comentam que alguns policiais ainda não compreenderam a importância dos materiais didáticos para o processo de ensino e aprendizagem. Porém, essa falta de apoio dos militares não é consensual. Alguns docentes manifestaram-se favoráveis às prioridades estabelecidas pelos militares, dizendo que o colégio sempre foi muito bem preparado do ponto de vista pedagógico e que existem "coisas mais urgentes para serem feitas". Essa postura foi percebida em $16,66 \%$ dos docentes entrevistados.

Quanto à organização escolar, os docentes são unânimes em afirmar que o coordenador pedagógico consegue estar mais disponível para os docentes pelo fato de existir uma coordenação disciplinar (formada exclusivamente por policiais) para cuidar da disciplina dos alunos.

Outro ponto a ser destacado diz respeito ao uniforme, utilizado tanto por alunos como pelos funcionários. Em relação aos funcionários e aos professores, em hipótese alguma se admite o cumprimento de suas funções sem as vestimentas obrigatórias, padronizadas para cada um dos grupos que trabalham na escola: professores de jaleco branco com o próprio nome bordado no lado esquerdo do peito; coordenadores pedagógicos com camisa bege e calça de tecido marrom; e demais funcionários (limpeza e cozinha) de camiseta bege e calça jeans. Todas essas peças devem ter a logomarca dos CEPMG no lado direito do peito. Em todas as situações (professores, administrativos e serviços diversos), o custo do uniforme é bancado pelo próprio funcionário. Essa vestimenta obrigatória deve estar sempre limpa, passada e bem cuidada.

As mesmas regras são aplicadas aos alunos. Nessa situação, destacamos dois pontos: o alto custo e a quantidade de peças que compõem o uniforme. Como não se admite que os estudantes frequentem as aulas ou que adentrem nas dependências da unidade escolar em seu horário de aula com o uniforme incompleto, cada aluno precisa desembolsar a quantia de $\mathrm{R} \$ 701,50$ para adquirir as 17 peças $^{6}$. Para amenizar o alto custo dos uniformes e possibilitar seu uso pelos alunos de famílias de baixa renda, 10\% do montante arrecadado com as contribuições voluntárias de cada unidade de CPMG “[será destinado] ao Serviço Social voltado para o bem-estar dos estudantes do Colégio Militar” (GOIÁS, 2017). Isso comporta, na interpretação dos professores da unidade pesquisada, a aquisição do uniforme para os alunos que não podem comprá-lo, contudo não há dados sobre o número de estudantes beneficiados pela medida, e não se sabe se ela seria extensiva a todas as peças do uniforme.

A composição do quadro de funcionários nesse novo modelo de gestão apresenta algumas curiosidades. Tomamos dois pontos para análise: os anos de 2014 (anterior à implantação da gestão militar) e 2018 (quando essa gestão já se encontrava consolidada). Em 2014, a escola contava com 42 funcionários; destes, 22 eram efetivos e 20 tinham contratos temporários. Em 2018, houve diminuição de dois funcionários (um auxiliar de secretaria e uma merendeira), totalizando 40 funcionários, com 19 efetivos e 21 com contratos temporários. Embora à primeira vista haja pouco a se considerar sobre esse ponto, uma análise mais aprofundada revela que em 2018 os concursados ocupavam cargos administrativos e os funcionários com contratos temporários assumiam as salas de aulas. O CPMG Cerrado contou com um reforço de 29 policiais militares para diferentes tarefas administrativas, conforme se configurou a militarização das escolas estaduais. Esses policiais recebem, de acordo com a lei goiana, uma Função Comissionada de Administração Militar (FCAM), cujos valores ultrapassam o montante pago aos diretores escolares das escolas estaduais geridas por professores.

Percebemos que essas mudanças visam projetar outro modelo de escola, que passa a ser desejado pelos pais/comunidade. Nesse sentido, o modelo militarizado ajusta-se à estratégia de desresponsabilização do estado em relação à educação pública, materializada pela cobrança da contribuição voluntária, e cria uma lógica 
de diferenciação na rede, endossando o argumento de que, "assim como os ricos podem escolher as escolas nas quais querem matricular seus filhos, também os pobres devem poder fazê-lo" (FREITAS, 2012, p. 386).

No que diz respeito à indisciplina, os docentes afirmam que ela é "menor" agora. Mesmo que ainda haja casos de indisciplina, esse assunto não faz mais parte da rotina diária do colégio. Quando ocorre algum fato, quem resolve são os policiais, por meio da coordenação disciplinar, considerada um suporte ao trabalho do professor:

Toda turma tem um para estragar o resto da turma. Tem umas turmas aí que tem uns quatro indisciplinados. Só que hoje é mais fácil lidar com eles. Antes a gente falava, falava... O professor morria de falar, de chamar a atenção e eles não ouviam. Então hoje eu percebo [que] eles ouvem mais. Eu não sei explicar como funciona esse trabalho militar, mas eles têm um jeito de dar uns "comandos" que fazem os alunos te ouvir e te atender melhor. Antes a gente esbravejava, gritava e o menino não parava para ouvir e quem dirá te atender. Hoje eu vejo que é mais fácil lidar com os alunos indisciplinados, porque, quando a gente chama a atenção, eles param, te ouvem e te atendem (Professor I).

O excesso de disciplinamento também foi apontado como entrave ao trabalho pedagógico: "Ao mesmo tempo que a disciplina ajuda, ela também atrapalha, pois em vários momentos pedagógicos a movimentação foi vista como bagunça" (Professor A). Esse modelo disciplinar busca reproduzir uma lógica de organização social na qual a disciplina possibilita produtividade, mas não se pode considerar que isso seja uma forma de conhecimento de saber. Consideramos que é bom desenvolver o exercício da obediência, mas não chegamos a compreender se esse nível de submissão pode gerar cidadãos com capacidade crítica ou indivíduos subservientes e passivos diante de fatos revoltantes com os quais possa se deparar. Consideramos que a obediência é produtiva, mas não pode levar o cidadão a uma cegueira política e a uma submissão à ordem instituída (SANTOS, 2015, p. 138-139).

Por último, destacamos a participação dos pais no acompanhamento da trajetória escolar dos estudantes no colégio militar onde esta pesquisa foi realizada. Para tanto, abordamos a mesma temática sob três olhares diferentes: o dos pais/responsáveis, o dos próprios alunos e o dos docentes. Como resultado, o consenso também se estabelece: todos os atores envolvidos concordam que os pais/responsáveis participam mais intensamente da trajetória escolar dos estudantes nesse colégio.

Do ponto de vista dos pais/responsáveis, essa maior participação deve-se à cobrança dos policiais, ao medo de perderem a vaga no colégio, ao desejo de que seus filhos sigam carreira militar, ingressem em uma universidade boa e incorporem regras e normas disciplinares. Também foram mencionados a segurança no colégio e o ensino de qualidade e, além disso, o fato de a escola "ser cidadã ética e defensora da moral e do civismo, buscando um desenvolvimento social e profissional” (Pai 27).

O bom acompanhamento familiar também foi destacado pelos funcionários e professores, que alegaram "ter pai na escola todo dia" depois que o colégio passou para a PM. Esses atores atribuem essa presença à mudança no perfil dos alunos e da própria família, bem como ao fato de pais/responsáveis e alunos se sentirem intimidados pelos policiais. Além disso, frisou-se que as famílias passaram a tratar os professores e os outros profissionais da instituição com mais respeito.

Acredito que a melhora no acompanhamento e presença dos pais se dá por duas razões: primeiro porque o pai se sente obrigado e intimidado a ir à escola quando solicitado, porque respeitam mais a figura do militar do que do civil; segundo porque o corpo discente mudou. Hoje temos outro perfil de pais e alunos (Professor J). 
Outra coisa que eu percebi que mudou foi a participação dos pais. Antes era um Deus nos acuda para trazer os pais na escola. Nossa! Era um sufoco. Você tinha que praticamente oferecer um banquete para os pais poderem vir na escola. Agora não. Você manda um convite e os pais estão em peso na escola, seja para qualquer coisa ou reunião... eles estão em peso na escola. Ainda tem aqueles que não aparecem, mas são poucos. A grande maioria está presente. A participação dos pais aumentou muito. A maioria aparece sem sequer foi convidado para uma conversa. Procura a coordenadora para saber como foi a semana. Quando a escola era civil, isso era muito raro. Os pais que vinham nas reuniões eram os pais dos meninos bons. Hoje é mais fácil levar os pais para a escola (Professor R).

Os docentes destacaram uma significativa queda na não realização de atividades extraclasse e de trabalhos escolares durante essa gestão e atribuem o fato ao "aumento da participação da família na vida dessas crianças e adolescentes".

\section{Do processo de militarização: algumas reflexões finais}

Analisando a militarização do CEPMG Cerrado, constatamos que esse processo tem efeitos rápidos sobre a organização da escola. O primeiro elemento diz respeito à infraestrutura. A escola sofreu mudanças significativas para se adequar ao padrão de um CEPMG, com pintura, troca de parte do mobiliário escolar em geral e reformulação dos espaços internos e da quadra de esporte. Além disso, a escola passou a ter internet e a organizar os espaços de forma a manter a hierarquia das novas relações militares presentes na escola; ganhou o reforço de 29 novos funcionários, isto é, 29 policiais militares que cuidam da parte administrativa e disciplinar da escola.

Essas transformações físicas e estruturais causam uma mudança no imaginário da comunidade, que, comparando o antes e o depois da escola, legitima o projeto de militarização, pois as melhorias são visíveis. Se, por um lado, essas mudanças revelam a transformação que a escola está vivendo, por outro não se questiona como esse processo acontece, especialmente como a escola consegue fazer esse milagre em tão pouco tempo.

O caso estudado oferece-nos boas inferências para analisar o processo: a primeira é a agilidade dos órgãos públicos, municipais e estaduais para atender aos pedidos do comandante-diretor da escola e fornecer o necessário para que a escola funcione. Nesse caso, a agilidade na legalização do terreno da escola e a chegada de novas carteiras indicam que não há entraves para a ação da PM na gestão da escola — situação muito diferente da luta diária dos diretores civis para conseguir realizar pequenas ações na escola, da burocracia que nunca resolve ao material que nunca chega. A segunda inferência diz respeito à cobrança da contribuição voluntária, que permite a entrada de recursos diretos para a execução da escola, sem a escassez e a dificuldade de acesso da escola a esses recursos e sem os inúmeros entraves e burocracias para a sua execução.

Com o dinheiro da contribuição voluntária dos pais é possível fazer o milagre e apresentar à comunidade uma escola a ser desejada, no entanto o tema provoca algumas reflexões inevitáveis: como é feita a prestação de contas do dinheiro arrecadado? Quais são os critérios utilizados para a aplicabilidade desse dinheiro? A arrecadação e a aplicação estão apresentadas de forma clara para a comunidade escolar? Se a gratuidade é um princípio constitucional, por que a Seduce faz vistas grossas para a cobrança dessa contribuição nos colégios militares?

Tais questões poderiam encerrar o assunto se não houvesse uma questão de fundo que nos leva a refletir sobre essa forma sutil de privatização da escola, uma vez que se estabelece uma fratura num princípio constitucional muito importante na luta pela educação como direito de todos que deve se materializar na escola pública, ou seja, a gratuidade da educação. Na medida em que esse modelo militar de educação institui a lógica de que se pagássemos uma pequena contribuição mensal teríamos uma escola de qualidade, compreendemos 
a gravidade da militarização de escolas como política educacional, que contribui para a criação de uma escola excludente. Nesse sentido, outra inquietação relaciona-se à essa temática: que escola seria reservada às famílias sem condições de manter os seus filhos e filhas nas escolas de educação militar?

Outra consequência refere-se ao controle e à disciplina impostos como norma a ser seguida na escola por professores, funcionários e estudantes, do uniforme obrigatório ao controle dos corpos dos alunos - e, de forma mais incisiva, das professoras e das alunas, que sofrem sanções no que tange ao corpo, aos adereços, ao modo de se portar. Outra forma de controle imposta aos professores é a orientação para que não participem de nenhum movimento grevista nem se vinculem a movimentos políticos questionadores da ordem estabelecida. No caso estudado, os professores que não se submeteram a essas exigências pediram remoção e mudaram de escola. Tudo isso indica um modelo autoritário de organização da escola, que impede tanto as manifestações de identidade de alunos e professores como o diálogo e a possibilidade de aprendizagem por meio das experiências de vida, capazes de valorizar os conhecimentos que cada um possui acerca da realidade escolar. Aqui o que interessa são o cumprimento do currículo oficial e o ensino da aprendizagem formal para os alunos.

Outro aspecto que se destaca no caso estudado é a mudança dos pais em relação à escola. Eles assumem um novo papel na educação dos filhos: atendem aos pedidos das escolas, com medo de que eles percam as suas vagas, e estão satisfeitos por terem uma instituição que cumpre com o papel de disciplinálos e de impor-lhes regras. Por isso, os pais indicam que essa escola é objeto de desejo: uma escola de ensino rigoroso, que ensina patriotismo, que oferece boas amizades, uma escola segura. Enquanto isso, a escola pública grita por uma maior participação dos pais, carecendo de apoio e acompanhamento da trajetória escolar dos estudantes. Do ponto de vista pedagógico, a participação e o apoio dos pais representam uma mudança importante para o sucesso escolar dos filhos.

Por fim, se a justificativa para militarizar a escola passa pela criação da imagem de uma escola segura, precisamos questionar qual conceito de segurança defendemos para a sociedade e se somente as escolas que compõem esse subsistema militar de educação são dignas de serem locais seguros. Também poderíamos indagar: qual é a relação, nesse sentido, entre segurança e controle social e dos corpos? A segurança é um direito de todos, assegurado em nossa Carta Magna, mas, quando afirmamos que apenas os estudantes que pertencem ao CPMG estão seguros, negamos o direito de todos a uma escola segura. Talvez a pergunta correta seja: se todos nós precisamos de segurança pública, tarefa a ser desempenhada primeiramente pela $\mathrm{PM}$, a polícia não deveria estar atuando nas ruas, garantindo a todos o direito à segurança? Seria correto o desvio desses profissionais para a gestão de escolas, garantindo a segurança de poucos? Essas questões também revelam uma política de segurança para poucos, que exclui grande parte da população. Talvez devêssemos terminar este artigo cantando com O Rappa ${ }^{7}$ :

\author{
A minha alma tá armada \\ E apontada para a cara \\ Do sossego \\ Pois paz sem voz \\ Paz sem voz \\ Não é paz é medo.
}

Por uma sociedade sem medo, por uma escola sem medo, escola pública, gratuita, cuja gestão deva ser exercida pelos profissionais da educação! Por paz com voz, com direito de exercer a liberdade e a diversidade em defesa da escola pública. 


\section{Contribuição dos Autores}

Problematização e Conceituação: Alves MF e Ferreira NSR; Metodologia: Alves MF e Ferreira NSR; Análise: Ferreira NSR; Redação: Alves MF.

\section{Notas}

1. O apelido foi utilizado como forma de preservar o anonimato da escola, conforme documentação aprovada pelo Comitê de Ética da Universidade Federal de Goiás.

2. Em entrevista concedida ao canal G1, por ocasião de argumentação contrária do Ministério Público de Goiás ao pagamento dessa contribuição, a comandante da unidade Hugo de Carvalho Ramos, Major Donizete Alves Pinto, afirma que ela se destina à manutenção da estrutura do colégio. Ainda segundo a comandante, "o padrão de qualidade continua, mas os extras, os benefícios a mais, esse conforto, nós não teremos mais a capacidade de continuar ofertando". Disponível em: <https://g1.globo.com/go/goias/noticia/pais-questionam-cobranca-de-taxas-de-matricula-e-mensalidade-emcolegios-militares-em-goias.ghtml>. Acesso em: 13 maio 2019.

3. A reportagem explora a temática da cobrança das taxas. Disponível em: <https://g1.globo.com/go/goias/noticia/paisquestionam-cobranca-de-taxas-de-matricula-e-mensalidade-em-colegios-militares-em-goias.ghtml>. Acesso em: 13 maio 2019 .

4. A promotora Maria Bernadete Ramos Crispim, em entrevista concedida ao jornal O Popular em 21 de novembro de 2017, diz que existem muitas denúncias no Ministério Público envolvendo esses colégios, entre as quais se destacam, principalmente, a cobrança de mensalidade, até com a emissão de carnês com 12 parcelas em algumas unidades de CEPMG. Disponível em: <https://www.opopular.com.br/editorias/cidades/pais-n\%C3\%A3o-precisam-pagarmensalidade-em-col\%C3\%A9gios-militares-1.1398702>. Acesso em: 13 maio 2019.

5. O CEMPG oferecia em 2017 um projeto de iniciativa solidária da instituição, três turmas de alfabetização e letramento para adultos no período noturno e contava com seis alunos com deficiência. $O$ tema da inclusão desses estudantes nos colégios militarizados ainda requer estudos e pesquisas.

6. Valores levantados no mês de junho de 2018 na Iovino Uniformes, empresa responsável pelo desenho do uniforme do primeiro CEPMG ainda em 1999 e que desde então atende aos estudantes dessas instituições escolares. Disponível em: <http://www.uniformecolegiomilitar.com.br/>. Acesso em: 26 jun. 2018.

7. Música composta por Alexandre Monte de Menezes, Lauro José de Farias, Marcelo de Campos Lobato, Marcelo Falcão Custodio e Marcelo Fontes do Nascimento Vi Santana.

\section{Referências}

ALVES, M. F.; TOSCHI, M. S.; FERREIRA, N. S. R. Os colégios militares em Goiás: processo de expansão e diferenciação da rede estadual. Retratos da Escola, Brasília, v. 12, n. 23, p. 271-287, jul./out. 2018. http:// doi.org/10.22420/rde.v12i23.865

COLÉGIO ESTADUAL DA POLÍCIA MILITAR DE GOIÁS (CEPMGO). Regimento Interno do Colégio Estadual da Polícia Militar de Goiás. Goiás: CEPMGO, 2017. Disponível em: <http://colegiomilitarpmvr. com.br/comunicado/RegimentoPronto.pdf>. Acesso em: 19 out. 2017.

FREITAS, L. C. Os reformadores empresariais da educação: da desmoralização do magistério à destruição do sistema público de educação. Educação e Sociedade, Campinas, v. 33, n. 119, p. 379-404, 2012. http:// dx.doi.org/10.1590/S0101-73302012000200004

GOVERNO DO ESTADO DE GOIÁS. Lei no 8.125, de 18 junho de 1976. Dispõe sobre a organização básica da Polícia Militar do Estado de Goiás e dá outras providências. Goiás, 1976. Disponível em: <http://www. gabinetecivil.goias.gov.br/leis_ordinarias/1976/lei_8125.htm>. Acesso em: 21 dez. 2017. 
GOVERNO DO ESTADO DE GOIÁS. Lei no 18.967, de 22 de julho de 2015. Dispõe sobre a transformação das unidades de ensino que especifica em Colégios Militares e dá outras providências. Goiás, 2015. Disponível em: <http://www.gabinetecivil.goias.gov.br/leis_ordinarias/2015/lei_18967.htm>. Acesso em: 17 maio 2019.

GOVERNO DO ESTADO DE GOIÁS. Lei no 19.679, de 13 de junho de 2017. Goiás, 2017. Disponível em: <http://www.gabinetecivil.go.gov.br/pagina_leis.php?id=21554>. Acesso em: 17 maio 2019.

GOIÁS. Secretaria de Estado de Educação, Cultura e Esporte. Organograma. Goiás: Seduce, 2018. Disponível em: <http://www.sgc.goias.gov.br/upload/arquivos/2018-01/seduce-1.jpg>. Acesso em: 14 dez. 2019.

GOIÁS. Termo de Cooperação Técnico Pedagógico no 14, de 25 de abril de 2017. Goiás, 2017.

OLIVEIRA, D. D. de. As escolas militares: o controle, a cultura do medo e da violência. In: CAETANO, I. de O.; VIEGAS, V. (orgs.). Estado de exceção escolar: uma avaliação crítica das escolas militarizadas. Aparecida de Goiânia: Escultura Produções Editoriais, 2016. p. 41-52.

SANTOS, R. dos. Genealogia dos Regimentos Internos do Colégio da Polícia Militar de Goiás. Goiânia: Gráfica UFG, 2015.

SANTOS, R. J. da C. A Militarização da escola pública em Goiás. 2016. Dissertação (Mestrado em Educação) - Pontifícia Universidade Católica de Goiás, Goiânia, 2016.

SOUZA, J. A elite do atraso: da escravidão à Lava Jato. Rio de Janeiro: Leya, 2017.

STECCA, K. Educação brasileira: quando a polêmica substitui as metas. Jornal UFG, Goiânia, 15 abr. 2019. Disponível em: <https://jornal.ufg.br/n/115801-educacao-brasileira-quando-a-polemica-substitui-asmetas>. Acesso em: 26 ago. 2019.

TAVARES, F. M. M. Quem quer manter a ordem? A ilegalidade da militarização das escolas em Goiás. In: CAETANO, I. de O.; VIEGAS, V. (orgs.). Estado de exceção escolar: uma avaliação crítica das escolas militarizadas. Aparecida de Goiânia: Escultura Produções Editoriais, 2016. p. 53-66.

\section{Sobre as Autoras}

Miriam Fábia Alves é doutora em Educação pela Universidade Federal de Minas Gerais. Professora no Programa de Pós-Graduação em Educação da Faculdade de Educação da Universidade Federal de Goiás (FE/UFG).

Neusa Sousa Rêgo Ferreira é mestre em educação pelo Programa de Pós-Graduação em Educação da Faculdade de Educação da Universidade Federal de Goiás (FE/UFG). Professora na Secretaria Municipal de Educação de Aparecida de Goiânia (GO) e na Secretaria de Estado de Educação, Cultura e Esporte de Goiás. Está disponível em http://www.sgc.goias.gov.br/upload/arquivos/2018-01/seduce-1.jpg

Recebido: 02 Jun 2019

Aceito: 18 Nov 2019 